\title{
CONSTRUÇÃO DE INICIADORES E OTIMIZAÇÃO DE ENSAIOS DE PCR E DE NESTED-PCR PARA A DETECÇÃO ESPECÍFICA DE Tritrichomonas foetus
}

\author{
PAULA ROGÉRIO FERNANDES ${ }^{1}$; ANDRÉA CAETANO DA SILVA²; MARIA LÚCIA GAMBARINI; \\ GUIDO FONTGALLAND C. LINHARES ${ }^{4}$
}

\begin{abstract}
FERNANDES, P.R.; SILVA, A.C.; GAMBARINI, M.L.G.; LINHARES, G.F.C. [Primers design and optimization of PCR and nested-PCR assays for the specific detection of Tritrichomonas foetus]. Construção de iniciadores e otimização de ensaios de pcr e de nested-PCR para a detecção específica de Tritrichomonas foetus. Revista Brasileira de Parasitologia Veterinária, v. 17, n. 3, p.133-138, 2008. Departamento de Medicina Veterinária Preventiva, Escola de Veterinária, Universidade Federal de Goiás. Campus Samambaia s/n. Goiânia, GO, 74.001-970. Brasil. E-mail: guidofcl@vet.ufg.br.

Tritrichomonas foetus is a pathogenic protozoan that causes a venereal disease in cattle known as bovine genital tricomonosis. In spite of the efficacy to recognize the target genomic DNA, the protocols so far developed for the diagnosis of this organism by PCR promote some inespecific amplifications or they are unable to discriminate $T$. foetus against other species within the genus. The objective of this study was to assess and optimize PCR and nested-PCR assays for the specific diagnosis of $T$. foetus, using novel primers selected from the alignment of sequences of the genes $18 \mathrm{~S}$ rRNA, 5.8S rRNA, 28S rRNA and of the internal transcribed spacers of the rDNA (ITS1 and ITS2). A pair of primers was constructed for the genus-specific amplification of a $648 \mathrm{bp}$ fragment and two others to amplify T. foetus species-specific fragments of 343 and $429 \mathrm{bp}$. No cross amplification was observed against Bos taurus genomic DNA neither against the DNA of usual bovine genital pathogens. Both, single and nested-PCR assays, presented analytical sensitivity to detect at least two $T$. foetus organisms.
\end{abstract}

KEY WORDS: Polymerase chain reaction, rDNA, molecular diagnosis, trichomonosis, bovine.

\section{RESUMO}

Tritrichomonas foetus é um protozoário patogênico responsável por doença venérea em bovinos conhecida por tricomonose genital bovina. A tricomonose bovina é uma doença venérea causada pelo protozoário cujo habitat natural é o trato genital. Os protocolos já desenvolvidos para o diagnóstico deste parasito por PCR, apesar de serem eficazes na identificação do DNA genômico alvo, promovem algumas amplificações inespecíficas ou são incapazes de distinguir $T$. foetus das outras espécies do gênero. O presente trabalho foi desenvolvido com o objetivo de estabelecer e otimizar protocolos de ensaio de PCR e nested-PCR para o diagnóstico es-

\footnotetext{
${ }^{1}$ Programa de Pós-Graduação em Ciência Animal, Universidade Federal de Goiás (UFG), Campus Samambaia, Caixa Postal 131, Goiânia, GO 74001-970, Brasil; Bolsista Capes. E-mail: paularogeriof@gmail.com

${ }^{2}$ Instituto de Patologia Tropical, UFG, Goiânia, GO. E-mail: andrea@iptsp.ufg.br

${ }^{3}$ Departamento de Medicina Veterinária (DMV), Escola de Veterinária (EV), UFG, Goiânia, GO. E-mail: mlgambarini@hotmail.com

${ }^{4}$ DMV, EV, UFG, Goiânia, GO. E-mail: guidofcl@vet.ufg.br
}

pecífico de T. foetus, empregando-se novos iniciadores, selecionados do alinhamento das seqüências dos genes 18S rRNA, 5,8S rRNA, 28S rRNA e dos espaços transcritos do rDNA (ITS1 e ITS2). Um par de iniciadores foi construído para amplificação gênero-específica de um fragmento de 648 pares de base e outros dois para a obtenção de produtos espécieespecíficos de 343 e 429 pb. Nenhuma reação cruzada foi observada frente ao DNA genômico de Bos taurus ou de microrganismos responsáveis por infecções genitais. A sensibilidade dos ensaios de PCR e de nested-PCR apresentados neste estudo permitiu um limiar de detecção de até dois parasitos.

PALAVRAS-CHAVE: reação em cadeia da polimerase, DNAr, diagnóstico molecular, tricomonose, bovinos.

\section{INTRODUÇÃO}

Tritrichomonas foetus (Riedmüller, 1928) é um protozoário flagelado, agente etiológico de doença infecciosa, sexualmente transmissível entre bovinos, denominada Tricomonose Genital Bovina (TGB).

No Brasil, apesar da escassez de publicações sobre o tema, 
existem registros que confirmam sua importância, devido a interferência com o desempenho reprodutivo nos plantéis (NEVES et al., 1999). Pellegrin e Leite (2003) apresentaram uma compilação de dados publicados por vários pesquisadores nacionais, com registros de prevalência para a TGB variando entre 1,88\% a 24\% em diferentes Estados.

Como os sinais clínicos não são patognomônicos, o diagnóstico conclusivo é realizado, convencionalmente, por meio das técnicas laboratoriais de microscopia direta e cultivo seletivo (PELLEGRIN, 1997). Como limitações destes métodos, apontam-se a baixa sensibilidade da microscopia direta e as dificuldades no cultivo que surgem quando são processadas amostras contaminadas, com baixa concentração de parasitos ou com parasitos inviáveis, levando quase sempre a resultados falso-negativos (RILEY et al., 1995; FELLEISEN et al., 1998).

Recentemente a reação em cadeia da polimerase (PCR) foi proposta como método alternativo, oferecendo como vantagens: maior sensibilidade e especificidade, rapidez na execução e automação (OIE, 2006). O teste de PCR oferece maior probabilidade de acerto, mesmo quando aplicado a amostras com parasitos inviáveis ou em cultivos com baixa concentração destes (PARKER et al., 2001). Esta propriedade propicia a redução do custo e do tempo de realização do diagnóstico, uma vez que pode reduzir o número de cultivos (PELLEGRIN: LEITE, 2003).

Ensaios de PCR, publicados recentemente para $T$. foetus demonstraram eficiência para detecção do DNA genômico alvo. No entanto, algumas reações indesejáveis têm sido observadas. Entre estas, amplificações inespecíficas do DNA de bovinos e de Trichomonas vaginalis (HO et al., 1994) ou a incapacidade de distinção entre os amplicons de T. foetus e de outras espécies do gênero, Tritrichomonas suis e Tritrichomonas mobilensis (FELLEISEN et al., 1998; NICKEL et al., 2002). Grahn et al. (2005) descreveram um protocolo de PCR para a detecção genérica de DNA, capaz de distinguir microrganismos dos gêneros Trichomonas, Tritrichomonas e Tetratrichomonas.

A escolha de iniciadores para a amplificação de DNA alvo de tricomonadídeos pela PCR tem sido realizada, com freqüência, a partir de seqüências dos genes correspondentes aos RNA ribossômicos (FELLEISEN et al., 1998; NICKEL et al., 2002; GRAHN et al., 2005). Esta opção se fundamenta no alto grau de conservação destes genes, entre isolados da mesma espécie, tornando-os adequados aos estudos filogenéticos (FELLEISEN, 1997).

O presente estudo teve como objetivos construir novos iniciadores a partir de seqüências dos genes 18S RNAr, 5,8S RNAr, 28S RNAr e os respectivos espaços transcritos ITS1 e ITS2 de T. foetus, avaliar e otimizar novos protocolos para ensaios da PCR e nested-PCR, para o diagnóstico específico de T. foetus.

\section{MATERIAL E MÉTODOS}

\section{Amostras de DNA de referência}

Para a avaliação dos ensaios da PCR propostos neste estudo, incluindo os testes de especificidade, foram utilizadas amostras de referência de DNA genômico de Bos taurus e dos microrganismos comumente presentes em infecções genitais de bovinos: Herpesvirus bovino tipo-1; Brucella abortus; B. melitensis; B. neotomae; B. ovis; B. suis, B. canis; sorovares de Leptospira interrogans (andamana, australis, autumnalis, bratislava, butembo, canicola, castellonis, cinoptery, copenhageni, djasiman, grippotyphosa, hardjo, hebdomadis, icterohaemorrhagiae, javanica, panama, patoc, pomona, pyrogenes, sentot, shermani, tarassovi, witcombi, wolffi); Campylobacter fetus venerealis; C. f. fetus; Ureaplasma diversum; M.ycoplasma bovigenitalium; M. bovis; Listeria monocytogenes; Neospora caninum; T. foetus (ATCCs 30166 e 50151) e T. suis (ATCC 30169).

\section{Extração de DNA genômico}

As amostras do DNA genômico dos microrganismos empregados no experimento foram extraídas pelo "kit" de extração $G F X^{T M}$ (Amersham Biosciences), a partir de culturas puras. Os produtos de extração (eluatos) foram armazenados a -20 ${ }^{\circ} \mathrm{C}$, em alíquotas de $5 \mu \mathrm{L}$ - volume utilizado nos testes de PCR.

\section{Seqüências utilizadas para desenho dos iniciadores}

Para a construção dos novos iniciadores gênero e espécieespecíficos obteve-se inicialmente, por acesso online ao GenBank (NCBI, 2005), as seqüências referentes aos genes 18S RNAr, 5,8S RNAr, 28S RNAr e aos espaços transcritos ITS1 e ITS2 das espécies do gênero Tritrichomonas e de outros tricomonadídeos. Dessa forma, foram obtidas as seqüências registradas sob os seguintes números de acesso: AY055799, AF466751, U85967 e Z18239 (T. foetus); AY055800 e U85966 (T. suis); AY055801 e U86612 (T. mobilensis); AY055802 e Z18261 (T. augusta); Z18255 (T. muris) U86613 (T.richomonas vaginalis); U86614 (T. gallinae); U86615 (T. tenax); AF340154 (Tetratrichomonas sp.) e AF342741 (Pentatrichomonas hominis).

\section{Desenho dos iniciadores}

As seqüências foram submetidas ao alinhamento genético pelo método de Clustal, empregando-se o software Megalin (DNAStar, Inc.). A seleção dos iniciadores seguiu critérios previamente estabelecidos por Lisby (1999) e Florida State University (2004). Os iniciadores selecionados foram, então, submetidos a avaliações de identidade molecular empregando-se a ferramenta BLAST ${ }^{\circledR}$ (Basic Local Alignment Search Tool) do GenBank (NCBI, 2005). Dessa forma foram definidos os seguintes iniciadores: gênero-específicos (TGF foward e TGR - reverse) e espécie-específicos para T. foetus (TEF - foward e TER2 - reverse) (Tabela 1).

Diferentes combinações entre iniciadores foram avaliadas visando a obtenção de produtos de diferentes tamanhos. $\mathrm{O}$ par TGF/TGR foi empregado para amplificação de fragmento gênero-específico de 628 pb e os pares TEF/TGR e TEF/ TER2 para fragmentos espécie-específicos de 429 e 343 pb, respectivamente (Tabela 2 ). 
Tabela 1. Seqüências de oligonucleotídeos iniciadores selecionados para a amplificação de fragmentos dos genes de Tritrichomonas foetus pela reação de PCR.

\begin{tabular}{lcccc}
\hline $\begin{array}{c}\text { Gene e n }{ }^{\circ} \text { de } \\
\text { acesso no } \\
\text { GenBank }\end{array}$ & Iniciador & $\begin{array}{c}\text { Seqüências } \\
\text { no gene }\end{array}$ & Posição & $\mathrm{T}_{\mathrm{a}}\left({ }^{\circ} \mathrm{C}\right)$ \\
\hline 18S RNAr(AF466751) & TGF & $5^{\prime}$-cac gtt atc tag agg aag ga-3' & $1459-1478$ & 53 \\
28S RNAr(Z18239) & TGR & $5^{\prime}$-ggc agc att ctc aag ctg c-3' & $211-193$ & 51 \\
5,8S RNAr(AF466751) & TEF & $5^{\prime}$-gcg ata agc ggc tgg att ag-3' & $1658-1677$ & 57 \\
28S RNAr(Z18239) & TER2 & 5'-cga ctc cag tta cgc tat g-3' & $125-107$ & 53 \\
\hline
\end{tabular}

TGF = "primer foward" gênero-específico; TGR = "primer reverse"gênero-específico; TEF = "primer forwar"d espécie-específico; TER2 = "primer reverse" espécie-específico; $\mathrm{T}_{\mathrm{a}}=$ temperatura de anelamento.

Tabela 2. Resultados de ensaios de PCR para a avaliação de diferentes combinações de pares de iniciadores gênero e espécie-específicos para $T$. foetus.

\begin{tabular}{lccc}
\hline $\begin{array}{c}\text { Pares de } \\
\text { niciadores }\end{array}$ & $\begin{array}{c}\text { Especificidade } \\
\text { esperada }\end{array}$ & $\begin{array}{c}\text { Resultados } \\
\text { de PCR }\end{array}$ & $\begin{array}{c}\text { Produto } \\
\text { de PCR }\end{array}$ \\
\hline TGF/TGR & gênero-específico & positivo & $628 \mathrm{pb}$ \\
TEF/TGR & espécie-específico & positivo & $429 \mathrm{pb}$ \\
TEF/TER2 & espécie-específico & positivo & $343 \mathrm{pb}$ \\
\hline
\end{tabular}

\section{Protocolo para PCR}

Estabeleceu-se inicialmente um protocolo padrão para as reações de PCR por meio de adaptações dos procedimentos descritos por Brent et al. (1994). A temperatura de anelamento $\left(\mathrm{T}_{\mathrm{a}}\right)$ foi calculada em função da quantidade das bases nitrogenadas conforme Ogliari et al. (2000).

O mix da reação padrão de PCR ficou estabelecido para um volume final de $50 \mu \mathrm{L}$ com os seguintes reagentes e concentrações finais: $20 \mathrm{mM}$ Tris- $\mathrm{HCl}+50 \mathrm{mM} \mathrm{KCl}$ (PCR buffer, Invitrogen); $2 \mathrm{mM} \mathrm{MgCl}$; 0,2 $\mathrm{mM}$ dNTP (Amersham Biosciences); $200 \mathrm{mM}$ para cada iniciador; $1,25 \mathrm{U}$ de Taq DNA Polimerase (Invitrogen); água ultra pura esterilizada q.s.p. (DNase/RNase-Free Distilled Water - Invitrogen). As amostras de DNA genômico foram inoculadas no volume de $5 \mu \mathrm{L}$.

As reações de amplificação foram realizadas em termociclador nas seguintes condições: desnaturação inicial por dois minutos a $94{ }^{\circ} \mathrm{C}$, seguido de 40 ciclos repetidos com temperaturas de $94^{\circ} \mathrm{C}$ por 30 segundos (desnaturação), 30 segundos (anelamento) e um minuto a $72{ }^{\circ} \mathrm{C}$ (extensão), finalizando a reação com uma etapa de extensão adicional a 72 ${ }^{\circ} \mathrm{C}$ por cinco minutos. Como controle positivo para as reações foi utilizado o DNA genômico extraído de amostra de referência de T. foetus (ATCC 30166). Água ultra pura esterilizada (DNase/RNase-Free Distilled Water - Invitrogen) foi utilizada como controle negativo.

\section{Otimização do ensaio de PCR}

Os iniciadores construídos neste estudo foram submetidos a avaliações de especificidade pela reação da PCR empregando-se as diferentes amostras de referência de DNA genômico citadas anteriormente.
Para a comprovação da identidade molecular, o produto da PCR obtido com o par de iniciadores espécie-específico TEF/TGR foi sequenciado (Sequenciador automático Megabace 1000 - Amersham Biotech ${ }^{\circledR}$ ) e a seqüência de nucleotídeos obtida foi submetida à avaliação pelo método do algoritmo BLAST ${ }^{\circledR}$, de acordo com Altschul et al. (1990).

O processo de otimização foi realizado conforme Persing (1993), avaliando-se diferentes concentrações de $\mathrm{MgCl}_{2}$, variações na $\mathrm{T}_{\mathrm{a}}$ e nos ciclos de temperatura no processo de amplificação.

As avaliações sobre o limiar de sensibilidade analítica das reações foram realizadas empregando-se amostras do DNA genômico de $T$. foetus extraído de amostra de cultura com concentração estimada por contagem em Câmara de Neubauer, segundo Ferreira Neto et al. (1977). As reações foram executadas em 5 diluições seriadas, na razão 10, a partir da concentração inicial de 3.750 parasitos $/ \mathrm{mm}^{3}(\mathrm{H}$ ”234 parasitos/5 $\mu \mathrm{L}$ ), conforme Felleisen et al. (1998).

\section{Protocolo de Nested-PCR}

Foi estabelecido um protocolo para ensaio de nested-PCR com base nos princípios descritos por Persing (1993), utilizando-se na primeira etapa de reação o par de iniciadores gênero-específico e na segunda, os iniciadores internos espécieespecíficos TEF/TGR.

O mix e o programa utilizado no termociclador para as etapas de nested-PCR foram os mesmos empregados para a reação da PCR, ajustando-se o número de ciclos para 40 na primeira etapa e 25 na segunda.

\section{Análise dos produtos amplificados}

Os produtos da PCR foram submetidos à eletroforese em gel de agarose a 1,5\% (Agarose NA-Amersham Biosciences), utilizando-se marcador de massa molecular de $100 \mathrm{pb}$ (DNA Ladder 100 bp - Invitrogen). A observação e documentação da eletroforese foram realizadas em transiluminador UV, após a coloração em brometo de etídio a $0,4 \mu \mathrm{g} / \mathrm{mL}$.

As reações, em todas as etapas de avaliação, foram realizadas em três repetições, sendo considerados válidos apenas os resultados com $100 \%$ de repetibilidade. 


\section{RESULTADOS E DISCUSSÃO}

Os resultados dos testes da PCR empregando quaisquer das combinações de iniciadores avaliadas (TGF/TGR, TEF/ TGR, TEF/TER) apresentaram resultados negativos frente ao DNA genômico de Bos taurus e dos microrganismos Herpesvirus bovino tipo-1, B. abortus, B. melitensis, B. neotomae, B. ovis, B. suis, B. canis, todos os sorovares de $L$. interrogans testados, C. fetus venerealis, C. f. fetus, $U$. diversum, $M$. bovigenitalium, $M$. bovis, $L$. monocytogenes e Neospora caninum.

Por outro lado, os mesmos pares de iniciadores TGF/TGR, TEF/TGR TEF/TER2 promoveram reações positivas em todas as repetições do teste com as amostras de referência do $T$. foetus empregadas, gerando os produtos esperados de 628, 429 e 343 $\mathrm{pb}$, respectivamente (Tabela 2). A eletroforese dos produtos da PCR, visualizada sob luz UV, não registrou ocorrência de bandas inespecíficas nas amostras utilizadas como controles.

Estes resultados demonstraram a eficiência dos iniciadores e protocolos aplicados nos testes da PCR para a discriminação de $T$. foetus entre os demais microrganismos que normalmente estão envolvidos em infecções do trato genital de bovinos.

Nenhuma amplificação inespecífica com DNA de bovino foi observada, garantindo, assim, a ausência dos resultados indesejáveis reportados por Ho et al. (1994) e Felleisen et al. (1998).

Com os pares espécie-específicos de iniciadores TEF/TGR e TEF/TER2 obteve-se os fragmentos alvo de 429 pb e 343 $\mathrm{pb}$, respectivamente, a partir do DNA genômico das amostras de referência de T. foetus (ATCC 30166 e 50151) e T. suis (ATCC 30169).

Tritrichomonas suis e T. foetus são tricomonadídeos encontrados, respectivamente, como comensal no trato gastrintestinal de suínos e como agente patogênico no aparelho genital de bovinos. A relação taxonômica entre estes organismos tem sido motivo de controvérsias desde quando foram originalmente descritos Gruby e Delafond (1843) e por

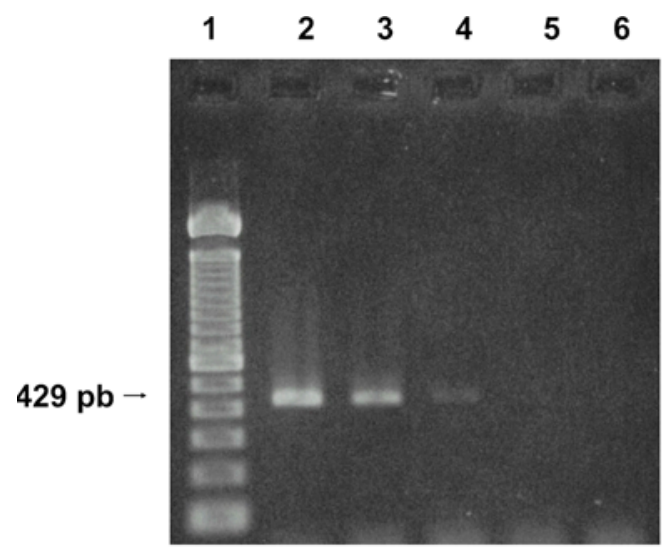

Riedmüller (1928), respectivamente. Estudos recentes têm demonstrado semelhanças entre ambos, com relação a todos os parâmetros avaliados, como morfologia (micro e ultra-estrutura), potencial patogênico, virulência, especificidade parasitária, características do cultivo in vitro, imunologia, bioquímica e biologia molecular (XU et al., 1998; TACHEZY et al., 2002; LUN et al., 2005). Existe, portanto, evidências científicas que sustentam a hipótese de se considerar T. suis e $T$. foetus como sinônimos. Esta questão encontra-se atualmente sob avaliação taxonômica na Comissão Internacional de Nomenclatura Zoológica.

A falha na discriminação entre o DNA de $T$. foetus e $T$. suis, pelo ensaio de PCR espécie-específico proposto neste trabalho, corrobora as observações dos autores supracitados. Outros estudos referentes ao diagnóstico de $T$. foetus por PCR já haviam chegado a conclusões semelhantes (FELLEISEN et al., 1998; NICKEL et al., 2002, GRAHN et al., 2005).

A avaliação, pelo algoritmo BLAST, da sequência do produto da PCR obtida com o par de iniciadores espécie-específico TEF/TGR, confirmou a identidade máxima para a sequência de T. foetus depositada no GenBank sob o número Z18239.

Os resultados referentes ao ensaio da nested-PCR, avaliado neste experimento, demonstraram efetividade do teste para a amplificação do fragmento alvo de 429 pb, obtido na segunda etapa de reação com o par de iniciadores espécie-específico interno TEF/TGR.

Os ensaios da PCR, assim como da nested-PCR, apresentaram resultados positivos para as amostras de DNA genômico de $T$. foetus correspondentes até dois parasitos, sendo este o limiar de sensibilidade detectado (Figura 1-A e B).

Apesar da leitura dos resultados de sensibilidade da nestedPCR terem sido equivalentes aos de PCR simples, a intensidade de visualização do produto de nested-PCR foi superior. Este fato pode ser atribuído à maior sensibilidade do primeiro em relação ao segundo, conforme Persing (1993) e Rebouças (2001).

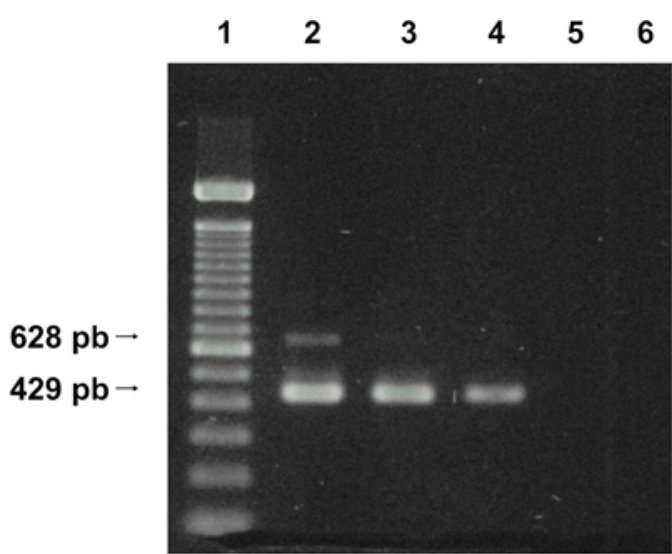

Figura 1. Eletroforese de fragmentos de 429 pb de Tritrichomonas foetus obtidos na avaliação de sensibilidade dos testes de PCR e de nested-PCR em amostras com diferentes concentrações de parasitos. (A) PCR simples: 1- marcador de 100 bp; 2- 234 parasitos; 3- 23 parasitos; 4- dois parasitos; 5- 0,2 parasito; 6- controle negativo. (B) nested-PCR: 1- marcador de 100 bp; 2- 234 parasitos e fragmento de 628 pb referente ao resíduo de amplificação da primeira etapa do nested-PCR; 3- 23 parasitos; 4- dois parasitos; 5- 0,2 parasito; 6- controle negativo. 
$\mathrm{Na}$ eletroforese do teste de nested-PCR com amostras de DNA correspondente a $\sim 234$ parasitos, registrou-se banda extra de 628 pb, relativa a resíduo da amplificação na primeira etapa da reação (Figura 1-B).

Os resultados das avaliações de sensibilidade analítica foram próximos aos publicados por Ho et al. (1994), Felleisen et al. (1998) e Nickel et al. (2002) referentes às reações simples da PCR, e por Gookin et al. (2002) com relação ao nestedPCR, os quais foram sensíveis para detectar um único parasito. Os testes de sensibilidade realizados neste estudo foram executados empregando-se diluições seriadas previamente estabelecidas no delineamento experimental. O nível de sensibilidade foi determinado em função dos resultados positivos referentes às diluições testadas e sua equivalência ao número de parasitos estimado, conforme Felleisen et al. (1998). Portanto o limiar de sensibilidade demonstrado neste estudo, tanto para o ensaio otimizado da PCR como para nested-PCR, pode ser considerado o nível máximo esperado, uma vez que a maior diluição positiva foi a de $10^{-2}$ ( $\sim 2$ parasitos), e que a diluição seguinte de $10^{-3}$, cujo resultado foi negativo, era correspondente a menos de 1 parasito $(\sim 0,2)$.

\section{CONCLUSÕES}

Com base nos resultados obtidos e considerando-se as condições em que o trabalho foi desenvolvido, pôde-se concluir que:

Os novos pares de iniciadores TEF/TER2 e TEF/TGR são efetivos para reações de a amplificação pela PCR dos respectivos fragmentos de 343 e 429 pb, espécie-específicos, localizados na seqüência dos genes $5,8 \mathrm{~S}$ rRNA, $28 \mathrm{~S}$ rRNA e o segundo espaço transcrito ITS2 de T. foetus.

As combinações dos pares de iniciadores TGF/TGR e TEF/ TGR são adequados para a detecção de um produto final, espécie-específico, de $429 \mathrm{pb}$ da seqüência dos genes $5,8 \mathrm{~S}$ rRNA, 28S rRNA e do segundo espaço transcrito do rDNA ITS2 de T. foetus por meio da reação da nested-PCR.

Agradecimentos:- Para a execução do experimento contou-se com colaborações importantes na obtenção de amostras de referência de DNAs genômicos, pelas quais agradecemos: $D^{2}{ }^{\text {a }}$. Willia M. E. D. de Brito (IPTSP/UFG); Dr.Sílvio Arruda Vasconcelos (Depto. Med. Vet. Prev. e Saúde Animal/FMVZ/ USP); Dr. Andrey Pereira Lage (Depto. Med. Vet. Prev./EV/ UFMG); Dra . Maristela Cardoso (Instituto Biológico de São Paulo/NURAIB); Dr. Elmiro Rosendo do Nascimento (Depto. Saúde Coletiva Vet. e Saúde Pública/UFF); Dr. Gustavo Freneau (Depto. Patobiologia Fac. Vet./ Kansas State University).

\section{REFERÊNCIAS BIBLIOGRÁFICAS}

ALTSCHUL, S.F.; GISH, W.; MILLER, W.; MYERS, E.W.; LIPMAN, D.J. Basic local alignment search tool. Journal of Molecular Biology, v.215, n.3, p.403-410, 1990.

BRENT, R.; KINGSTON, R.E.; SEIDMAN, J.G.; STRUHL, K.; AUSUBEL, F.M.; CHANDA, V.B.; MOORE, D.D.
Current protocols in molecular biology. New York: John Wiley \& Sons, 1994. 1600 p.

FELLEISEN, R.S.J. Comparative sequence analysis of $5.8 \mathrm{~S}$ rRNA genes and internal transcribed spacer (ITS) regions of trichomonadid protozoa. Parasitology, v.115, n.2, p.111119, 1997.

FELLEISEN, R.S.J.; LAMBELET, N.; BACHMANN, P.; NICOLET, J.; MÜLLER, N.; GOTTSTEIN, B. Detection of Tritrichomonas foetus by PCR and DNA enzyme immunoassay based on rRNA gene unit sequences. Journal of Clinical Microbiology, v.36, n.2, p.513-519, 1998.

FERREIRANETO, J.M.; VIANA, E.S.; MAGALHÃES, L.M. Patologia clínica veterinária. Belo Horizonte: Rabelo Brasil, 1977. $279 \mathrm{p}$.

FLORIDA STATE UNIVERSITY. Primer design. Disponível em: <http:// www.bio.fsu.edu/seq-fac/ PrimerDesign.html >. Acesso em: 15 jan. 2004.

GOOKIN, J.L.; BIRKENHEUER, A.J.; BREITSCHWERDT, E.B.; LEVY, M.G. Single-tube nested PCR for detection of Tritrichomonas foetus in feline feces. Journal of Clinical Microbiology, v.40, n.11, p.4126-4130, 2002.

GRAHN, R.A.; BonDURANT, R.H.; HOOSEAR, K.A. van; WALKER, R.L.; LYONS, L.A. An improved molecular assay for Tritrichomonas foetus. Veterinary Parasitology, v.127, n.1, p.33-41, 2005.

GRUBY, D.; DELAFOND, H.M.O. Recherches sur des animalcules se développant en grand nombre dans 1 'estomac et dans les intestins, pedant la digestion des animaux herbivores et carnivores. Comptes Rendus de l'Académie des Sciences, v.17, p.1304-1308, 1843.

HO, M.S.Y.; CONRAD, P.A.; LEFEBVRE, R.B.; PEREZ, E.; BONDURANT, R.H. Detection of bovine trichomoniasis with a specific DNA probe and PCR amplification system. Journal of Clinical Microbiology, v.32, n.1, p.98-104, 1994.

LISBY, G. Application of nucleic acid amplification in clinical microbiology. Molecular Biotechnology, v.12, n.2, p.7599, 1999.

LUN, Z.R.; CHEN, X.G.; ZHU, X.Q.; LI, X.R.; XIE, M.Q. Are Tritrichomonas foetus and Tritrichomonas suis synonyms? Trends in Parasitology, v.21, n.3, p.122-125, 2005.

NCBI - NATIONAL CENTER FOR BIOTECHNOLOGY INFORMATION. The entrez nucleotides database. Disponível em: <http://www.ncbi.nlm.nih.gov/entrez/ query.fcgi?db=Nucleotide $>$. Acesso em: 20 mar. 2005.

NEVES, J.P.; GONÇALVES, P.B.D.; OLIVEIRA, J.F.C. Fatores que afetam a eficiência reprodutiva na vaca. Revista Brasileira de Reprodução Animal, v.23, n.2, p.99-109, 1999.

NICKEL, D.D.; OLSON, M.E.; SCHULTZ, G.A. An improved polymerase chain reaction assay for the detection of Tritrichomonas foetus in cattle. Canadian Veterinary Journal, v.43, n.3, p.213-216, 2002.

OIE. Manual of diagnostic tests and vaccines for terrestrial animals: trichomonosis (chapter 2.3.6). Disponível em:< 
http://www.oie.int/eng/normes/mmanual/A_00057.htm>. Acesso em 12 jan, 2006.

OGLIARI, J.B.; BOSCARIOL, R.L.; CAMARGO, L.E.A. Optimization of PCR amplification of maize microsatellite loci. Genetics and Molecular Biology, v.23, n.2, p.395-398, 2000.

PARKER, S.; LUN, Z.R.; GAJADHAR, A. Application of a PCR assay to enhance the detection and identification of Tritrichomonas foetus in cultured preputial samples. Journal of Veterinary Diagnostic Investigation, v.13, n.6, p.508-513, 2001.

PELLEGRIN, A.O. Tricomonose bovina (Bovine trichomoniasis). In: SIMPÓSIO PFIZER SOBRE DOENÇAS INFECCIOSAS E VACINAS PARA BOVINOS, 2.1997, Caxambu. Anais... Caxambu: PFIZER1997.p. 6065.

PELlEGRIN, A.O.; LEITE, R.C. Atualização Sobre Tricomonose Genital Bovina. Corumbá: Embrapa Pantanal, 2003. $18 \mathrm{p}$.

PERSING, D.H.; SMITH, T.F.; TENOVER, F.C.; WHITE, T.J. Diagnostic molecular microbiology - principles and applications. Washington: Library of Congress Catalogingin-Publication Data, 1993. 641 p.
REBOUÇAS, N.A. Biologia molecular aplicada à medicina: fundamentos teóricos e práticos, 1.ed. São Paulo: Universidade de São Paulo, 2001. 66 p. [Apostila]

RIEDMÜLLER, L. Über die morphologie, überträgungsversuche, und klinische bedeutung der beim sporadischen abortus des rindes vorkommenden Trichomonaden. Zentralblatt für Bakteriologie, Parasitenkunde, Infektionskrankheiten und Hygiene, v.1, n.108, p.103-118, 1928.

RILEY, D.E.; WAGNER, B.; POLLEY, L.; KRIEGER, J.N. PCR-based study of conserved and variable DNA sequences of Tritrichomonas foetus isolates from Saskatchewan, Canada. Journal of Clinical Microbiology, v.33, n.5,p.13081313, 1995.

TACHEZY, J.; TACHEZY, R.; HAMPL, V.; SEDINOVA, M.; VANACOVA, S.; VRLIK, M.; VAN-RANST, M.; FLEGR. J.; KULDA, J. Cattle pathogen Tritrichomonas foetus (Riedmuller, 1928) and pig commensal Tritrichomonas suis (Gruby \& Delafond, 1843) belong to the same species. Journal of Eukaryotic Microbiology, v.49, n.2, p.154-163, 2002.

XU, W.D.; LUN, Z.R.; GAJADHAR, A. Chromosome numbers of Tritrichomonas foetus and Tritrichomonas suis. Veterinary Parasitology, v.78, n.4, p.247-251, 1998.

Recebido em 30 de outubro de 2006.

Aceito para publicação em 10 de julho de 2008. 